Article

\title{
Luminescence Tuning of Fluorinated Bistolanes via Electronic or Aggregated-Structure Control
}

\author{
Masato Morita ${ }^{1}$, Shigeyuki Yamada ${ }^{1, * \mathbb{C}}$, Tomohiro Agou ${ }^{2} \mathbb{D}$, Toshio Kubota ${ }^{2}$ and \\ Tsutomu Konno ${ }^{1}$ \\ 1 Faculty of Molecular Chemistry and Engineering, Kyoto Institute of Technology, Matsugasaki, Sakyo-ku, \\ Kyoto 606-8585, Japan; kit.fusso.201602@gmail.com (M.M.); konno@kit.ac.jp (T.K.) \\ 2 Department of Quantum Beam Science, Graduate School of Science and Engineering, Ibaraki University, \\ 4-12-1 Nakanarusawa, Hitachi, Ibaraki 316-8511, Japan; tomohiro.agou.mountain@vc.ibaraki.ac.jp (T.A.); \\ toshio.kubota.organicchem@vc.ibaraki.ac.jp (T.K.) \\ * Correspondence: syamada@kit.ac.jp; Tel.: +81-75-724-7517
}

Received: 25 April 2019; Accepted: 6 May 2019; Published: 9 May 2019

Abstract: Organic luminescent materials have a wide range of practical applications, but the understanding of the relationship between molecular structure and luminescent behavior is lacking. Herein, we synthesized fluorinated bistolanes with an electron-donating alkoxy substituent at one terminal and an electron-withdrawing substituent at the other to realize systematic control of the electron-density distribution. Evaluation of the phase transition behavior revealed that most of the fluorinated bistolanes showed liquid-crystalline (LC) behavior, with the phase transition temperature depending on the terminal substituents. Additionally, the fluorinated luminophores displayed intense photoluminescence (PL) in solution and in their crystal phases. Remarkably, the PL color shifted dramatically depending on the dipole moment $\left(\mu_{\|}\right)$along the long molecular axis; thus, PL tuning can be achieved through electronic modulation by precise control of the $\mu_{\|}$of the luminophore. Interestingly, in the LC phases under thermal conditions, the maximum PL band shifted by $0.210 \mathrm{eV}$ upon phase transition from the crystal to smectic A LC phases, indicating that PL tuning can also be achieved by controlling the aggregated structure. These results offer a new molecular design for easily tunable PL materials using the molecular properties or external stimuli for promising applications, including light-emitting displays and PL sensing materials.

Keywords: fluorine; $\pi$-conjugated molecules; photoluminescence; liquid crystals; electron-density distribution

\section{Introduction}

Organic luminescent materials can be broadly classified into two groups: solution-state and solid-state luminophores. Solution-state luminophores, such as rhodamine and fluorescein, are applicable in biomedical imaging and optical probes [1-4], whereas solid-state luminophores are typically employed in lighting devices, light-emitting diodes, and electroluminescence devices [5-9]. To realize practical applications, significant efforts have been devoted to the discovery of novel luminescent materials, and as a result, various kinds of luminescent molecules have been developed $[10,11]$. However, there have been few systematic studies on the relationship between molecular structure and luminescent behavior, even though luminescence tuning is a key feature for practical light-emitting applications.

Over the past few decades, numerous fluorine-containing organic materials have been developed because chemical reactivity and material properties are dramatically influenced by the unique characteristics of fluorine, e.g., the largest electronegativity of all elements, the second smallest atom 
next to hydrogen, and the strong dissociation energy of C-F bonds [12,13]. Our group has extensively studied efficient synthetic protocols for organofluorine molecules containing $\mathrm{CF}_{3}$ groups $[14,15]$ and $\mathrm{CF}_{2} \mathrm{CF}_{2}$ fragments [16,17]. More recently, we have also developed a significant interest in functional materials, e.g., liquid-crystalline (LC) and photoluminescence (PL) materials, based on fluorinated $\pi$-conjugated molecules such as pentafluorophenyl-containing tolane [18] and bistolane molecules [19-23]. Intriguingly, bistolanes $\mathbf{1 a A}$ and $\mathbf{1 b A}$ (Figure 1a) exhibited blue-light PL in solution as well as in crystalline ( $\mathrm{Cr}$ ) phases [23]. Remarkably, $\mathbf{1 a A}$ and $\mathbf{1 b A}$ in the LC phases under thermal conditions also displayed PL behavior, with the PL intensity and color reversibly changing during the thermal $\mathrm{Cr} \rightleftarrows$ LC phase transition.

(a)

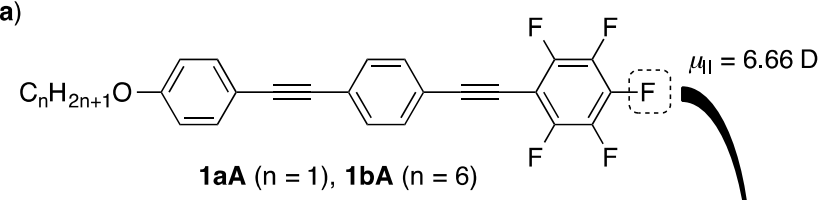

$\begin{array}{ll}\text { 1aA: } & \frac{\text { in solution }}{\lambda_{\mathrm{PL}}=403 \mathrm{~nm}\left(\Phi_{\mathrm{PL}}=0.79\right)} \frac{\text { in crystal }}{\lambda_{\mathrm{PL}}=419 \mathrm{~nm}\left(\Phi_{\mathrm{PL}}=0.66\right)} \\ \text { 1bA: } \lambda_{\mathrm{PL}}=407 \mathrm{~nm}\left(\Phi_{\mathrm{PL}}=0.76\right) & \lambda_{\mathrm{PL}}=450 \mathrm{~nm}\left(\Phi_{\mathrm{PL}}=0.47\right)\end{array}$

(b)

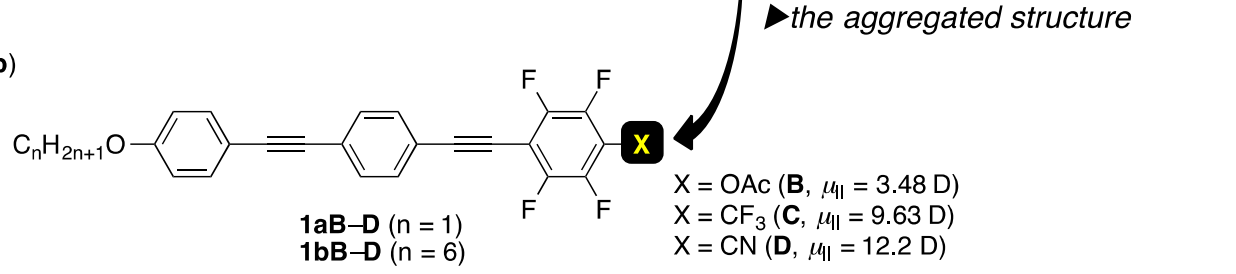

Figure 1. Molecular structures used in (a) a previous study and (b) the present work. $\mu_{\|}$: Calculated dipole moment along the long molecular axis.

Previous studies by our research group on fluorinated bistolane-type luminophores have demonstrated that the PL behavior depends on the electron-density distribution or aggregated structure. To gain deeper insights into the PL behavior, in this study, we designed six fluorinated bistolanes, viz., 1aB-D and $\mathbf{1 b B}-\mathbf{D}$, by systematically modulating the electron-density distribution. Herein, we describe the molecular design and synthesis of these fluorinated bistolane-type luminophores as well as their LC and PL behaviors. Additionally, the effect of precisely modulating the electron-density distribution or aggregated structure on the PL behavior is discussed.

\section{Materials and Methods}

\subsection{General}

${ }^{1} \mathrm{H}$ and ${ }^{13} \mathrm{C}$ NMR spectra were recorded using a Bruker AVANCE III 400 NMR spectrometer $\left({ }^{1} \mathrm{H}\right.$ : $400 \mathrm{MHz}$ and ${ }^{13} \mathrm{C}: 100 \mathrm{MHz}$, Bruker Corporation, Rheinstetten, Germany) in chloroform-d $\left(\mathrm{CDCl}_{3}\right)$ solution, and the chemical shifts are reported in parts per million (ppm) using the residual proton in the NMR solvent $\left(\delta_{\mathrm{H}}=7.26 \mathrm{ppm}\right.$ for $\mathrm{CHCl}_{3}$ and $\delta_{\mathrm{C}}=77 \mathrm{ppm}$ for $\left.\mathrm{CDCl}_{3}\right) \cdot{ }^{19} \mathrm{~F} \mathrm{NMR}(376 \mathrm{MHz})$ spectra were recorded using a Bruker AVANCE III $400 \mathrm{NMR}$ spectrometer in $\mathrm{CDCl}_{3}$ solution with $\mathrm{CFCl}_{3}$ $\left(\delta_{\mathrm{F}}=0 \mathrm{ppm}\right)$ as an internal standard. Infrared (IR) spectra were acquired via the $\mathrm{KBr}$ method using a JASCO FT/IR-4100 type A spectrometer (JASCO Corporation, Tokyo, Japan); all spectra are reported in wavenumbers $\left(\mathrm{cm}^{-1}\right)$. High-resolution mass spectroscopy (HRMS) was performed using a JEOL JMS-700MS spectrometer (JEOL Ltd., Tokyo, Japan) via fast atom bombardment (FAB). All reactions were performed using dried glassware with a magnetic stirrer bar. All chemicals were of reagent grade and, if necessary, were purified in the usual manner prior to use. Column chromatography was conducted on silica gel (Wako-gel@60N, 38-100 $\mu \mathrm{m}$, FUJIFILM Wako Pure Chemical Corporation, Osaka, Japan) and thin layer chromatography (TLC) was performed on silica gel TLC plates (Merck, Silica gel $60 \mathrm{~F}_{254}$, FUJIFILM Wako Pure Chemical Corporation, Osaka, Japan). 


\subsection{Synthesis}

Fluorinated bistolanes $\mathbf{1 a B}-\mathbf{D}$ and $\mathbf{1 b B}-\mathbf{D}$ were synthesized according to the synthetic procedure shown in Scheme 1. Acetoxy (AcO)-substituted bistolanes $\mathbf{1 a B}$ and $\mathbf{1 b B}$ were prepared by the $\operatorname{Pd}(0)$-catalyzed Sonogashira cross-coupling reaction of 4-[2-(4-alkoxyphenyl)ethyn-1-yl]phenylacetylene $\mathbf{3} \mathbf{a}$ or $\mathbf{3} \mathbf{b}$, readily accessible from the corresponding (4-alkoxyphenyl)acetylene $\mathbf{2 a}$ or $\mathbf{2 b}$ [21,23], with 4-acetoxy-2,3,5,6-tetrafluoroiodobenzene (B). Derivatives $1 \mathrm{aC}$ or $\mathbf{1 b C}$ with a trifluoromethyl $\left(\mathrm{CF}_{3}\right)$ group and $\mathbf{1 a D}$ or $\mathbf{1 b D}$ with a cyano $(\mathrm{CN})$ group were prepared by the nucleophilic addition of a lithium acetylide, generated from $3 \mathbf{a}$ or $3 \mathbf{b}$ and $n$-butyllithium, to perfluorotoluene (C) or perfluorobenzonitrile (D), followed by elimination of lithium fluoride. The following sections provide typical synthetic procedures for the preparation of bistolanes 1aB-D with a methoxy $\left(\mathrm{CH}_{3} \mathrm{O}\right)$ substituent.

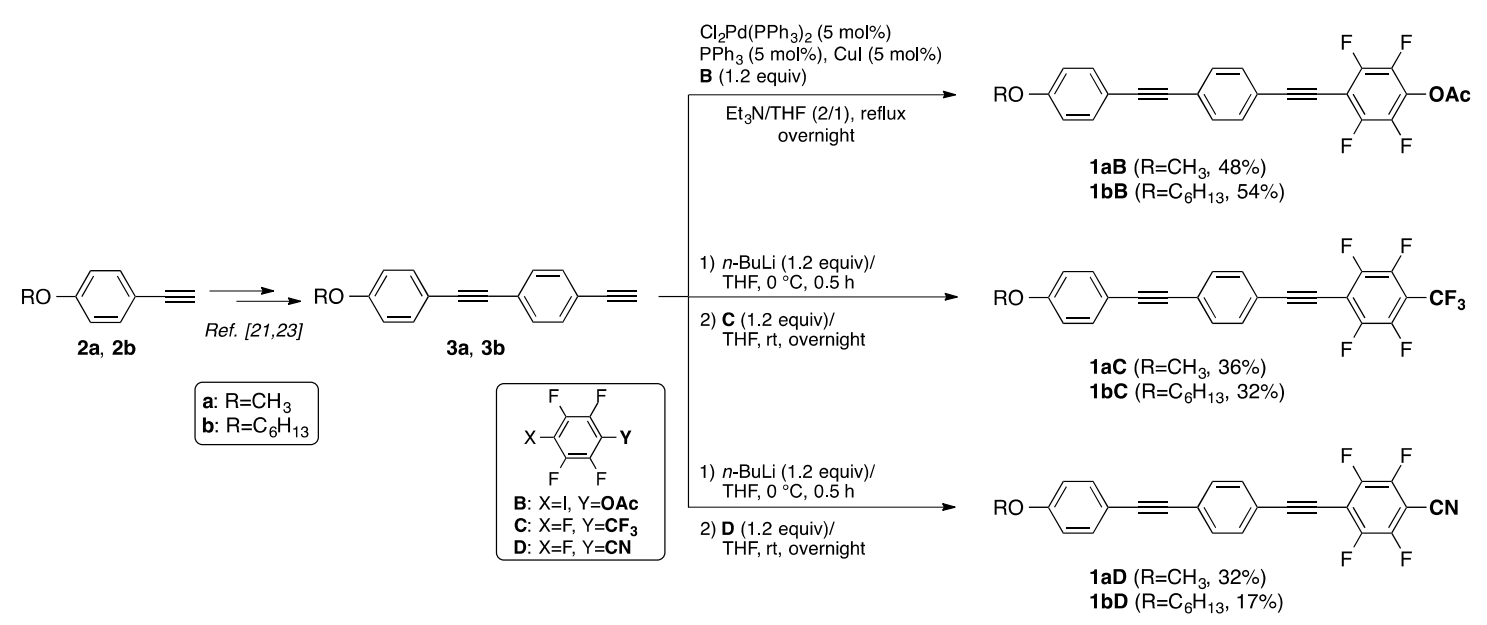

Scheme 1. Synthetic procedures for fluorinated bistolanes 1aB-D and 1bB-D.

\subsection{Preparation of AcO-Substituted Bistolane 1aB}

In a $50 \mathrm{~mL}$ two-necked round-bottomed flask were placed $\mathrm{Cl}_{2} \mathrm{Pd}\left(\mathrm{PPh}_{3}\right)_{2}(0.051 \mathrm{~g}, 0.050 \mathrm{mmol}), \mathrm{PPh}_{3}$ (0.015 g, $0.050 \mathrm{mmol}), \mathrm{CuI}(0.031 \mathrm{~g}, 0.10 \mathrm{mmol}), 4$-[2-(4-methoxyphenyl)ethyn-1-yl]phenylacetylene (3a, $0.24 \mathrm{~g}, 1.0 \mathrm{mmol})$, and 4-acetoxy-2,3,5,6-tetrafluoroiodobenzene (B, $0.41 \mathrm{~g}, 1.2 \mathrm{mmol})$ in $\mathrm{Et}_{3} \mathrm{~N}(10 \mathrm{~mL})$ and THF $(5 \mathrm{~mL})$. The mixture was stirred at reflux temperature overnight. The precipitate formed in the reaction mixture was separated by atmospheric filtration and the filtrate was poured into saturated aqueous $\mathrm{NH}_{4} \mathrm{Cl}$ solution $(20 \mathrm{~mL})$. The crude product was extracted using AcOEt ( $20 \mathrm{~mL}$, three times) and washed with brine $\left(20 \mathrm{~mL}\right.$, once). The organic layer was dried over anhydrous $\mathrm{Na}_{2} \mathrm{SO}_{4}$, filtered, and concentrated using a rotary evaporator. The resultant crude product was purified by silica-gel column chromatography using hexane/AcOEt $(20: 1, v / v)$ as an eluent, providing coupling product $\mathbf{1 a B}$ $(0.21 \mathrm{~g}, 0.48 \mathrm{mmol})$ in $48 \%$ yield as a white solid. This product was recrystallized by slow evaporation from $\mathrm{CH}_{2} \mathrm{Cl}_{2} / \mathrm{MeOH}(1: 1, v / v)$ to obtain $1 \mathrm{aB}$ in crystalline form.

2.3.1. 1-Acetoxy-2,3,5,6-tetrafluoro-4-[2-[4-[2-(4-methoxyphenyl)ethyn-1-yl]phenyl]ethyn-1yl]benzene (1aB)

Yield: $48 \%$ (white solid); mp: $159^{\circ} \mathrm{C}$ determined by differential scanning calorimetry (DSC); ${ }^{1} \mathrm{H}$ $\operatorname{NMR}\left(\mathrm{CDCl}_{3}\right): \delta 2.42(\mathrm{~s}, 3 \mathrm{H}), 3.84(\mathrm{~s}, 3 \mathrm{H}), 6.88-6.91(\mathrm{~m}, 2 \mathrm{H}), 7.47-7.57(\mathrm{~m}, 6 \mathrm{H}) ;{ }^{13} \mathrm{C} \mathrm{NMR}\left(\mathrm{CDCl}_{3}\right): \delta$ 20.0, 55.4, $75.3(\mathrm{t}, J=4.0 \mathrm{~Hz}), 87.8,92.3,101.6(\mathrm{t}, J=3.8 \mathrm{~Hz}), 102.3(\mathrm{t}, J=18.0 \mathrm{~Hz}), 114.0,114.9,121.0$, $125.1,129.3(\mathrm{tt}, J=14.7,2.9 \mathrm{~Hz}), 131.6,132.0,133.3,139.5-142.2\left(\mathrm{~m}, C_{\mathrm{Ar}}-\mathrm{F}, 1 \mathrm{C}\right), 145.6-148.4\left(\mathrm{~m}, C_{\mathrm{Ar}}-\mathrm{F}\right.$, 1C), 160.1, 166.6; ${ }^{19} \mathrm{~F} \mathrm{NMR}\left(\mathrm{CDCl}_{3}\right): \delta-137.34(\mathrm{dd}, J=23.9,9.9 \mathrm{~Hz}, 2 \mathrm{~F}),-153.66(\mathrm{dd}, J=23.9,9.9$

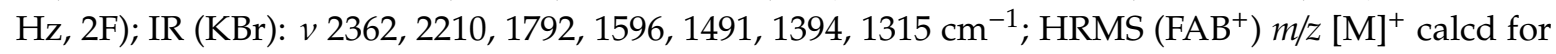
$\mathrm{C}_{25} \mathrm{H}_{14} \mathrm{O}_{3} \mathrm{~F}_{4}$ : 438.0879; found: 438.0881. 
2.3.2. 1-Acetoxy-2,3,5,6-tetrafluoro-4-[2-[4-[2-(4-hexyloxyphenyl)ethyn-1-yl]phenyl]ethyn-1yl]benzene (1bB)

Yield: $54 \%$ (white solid); mp: $143{ }^{\circ} \mathrm{C}$ determined by DSC; ${ }^{1} \mathrm{H}$ NMR $\left(\mathrm{CDCl}_{3}\right): \delta 0.91(\mathrm{t}, J=7.0$ $\mathrm{Hz}, 3 \mathrm{H}), 1.32-1.37(\mathrm{~m}, 4 \mathrm{H}), 1.43-1.50(\mathrm{~m}, 2 \mathrm{H}), 1.76-1.83(\mathrm{~m}, 2 \mathrm{H}), 3.42(\mathrm{~s}, 3 \mathrm{H}), 3.98(\mathrm{t}, J=6.6 \mathrm{~Hz}, 2 \mathrm{H})$, 6.87-6.89 (m, 2H), 7.45-7.48 (m, 2H), 7.50-7.56 (m, 4H); ${ }^{13} \mathrm{C}$ NMR $\left(\mathrm{CDCl}_{3}\right): \delta 14.2,20.1,22.7,25.8,29.3$, 31.7, 68.3, $75.3(\mathrm{t}, J=4.3 \mathrm{~Hz}), 87.7,92.5,101.6(\mathrm{t}, J=4.3 \mathrm{~Hz}), 102.4(\mathrm{t}, J=18.1 \mathrm{~Hz}), 114.8,121.0,125.2$, $129.3(\mathrm{tt}, J=17.6,2.9 \mathrm{~Hz}), 131.6,132.0,133.3,139.5-142.0\left(\mathrm{~m}, \mathrm{C}_{\mathrm{Ar}} \mathrm{F}, 1 \mathrm{C}\right), 145.7-148.3\left(\mathrm{~m}, \mathrm{C}_{\mathrm{Ar}}-\mathrm{F}, 1 \mathrm{C}\right)$, $159.7,166.6$ (one sp-carbon was overlapped with another alkyne carbon); ${ }^{19} \mathrm{~F} \mathrm{NMR}\left(\mathrm{CDCl}_{3}\right): \delta-137.90$ $(\mathrm{dd}, J=23.1,9.8 \mathrm{~Hz}, 2 \mathrm{~F}),-154.22(\mathrm{dd}, J=23.1,9.8 \mathrm{~Hz}, 2 \mathrm{~F}) ; \mathrm{IR}(\mathrm{KBr}): v 2962,2860,2367,2208,1795,1597$, 1495, $1405 \mathrm{~cm}^{-1}$; HRMS $\left(\mathrm{FAB}^{+}\right) \mathrm{m} / \mathrm{z}[\mathrm{M}]^{+}$calcd for $\mathrm{C}_{30} \mathrm{H}_{24} \mathrm{O}_{3} \mathrm{~F}_{4}$ : 508.1662; found: 508.1655 .

\subsection{Preparation of $\mathrm{CF}_{3}$-Substituted Bistolane 1 aC}

In a $50 \mathrm{~mL}$ two-necked round-bottomed flask was placed 4-[2-(4-methoxyphenyl)ethyn-1-yl]phenylacetylene (3a, $0.46 \mathrm{~g}, 2.0 \mathrm{mmol})$ in THF (30 $\mathrm{mL})$. The solution was cooled to $0{ }^{\circ} \mathrm{C}$ and then $n$ - $\mathrm{BuLi}\left(1.6 \mathrm{~mol} \mathrm{~L}^{-1}\right.$ hexane solution, $\left.1.3 \mathrm{~mL}, 2.0 \mathrm{mmol}\right)$ was added. The mixture was stirred at $0{ }^{\circ} \mathrm{C}$ for $0.5 \mathrm{~h}$. Then, perfluorotoluene $(\mathbf{C}, 0.42 \mathrm{~mL}, 3.0 \mathrm{mmol})$ was added dropwise at $0{ }^{\circ} \mathrm{C}$ and the resultant solution was continuously stirred at room temperature overnight. The reaction mixture was poured into saturated aqueous $\mathrm{NH}_{4} \mathrm{Cl}$ solution $(40 \mathrm{~mL})$. The crude product was extracted using AcOEt $(40 \mathrm{~mL}$, three times) and washed with brine $(40 \mathrm{~mL}$, once). The organic layer was dried over anhydrous $\mathrm{Na}_{2} \mathrm{SO}_{4}$, filtered, and concentrated using a rotary evaporator. The resultant crude product was purified by silica-gel column chromatography using hexane/AcOEt $(20: 1, v / v)$ as an eluent, yielding coupling product $1 \mathrm{aC}(0.32 \mathrm{~g}, 0.72 \mathrm{mmol})$ in $36 \%$ yield as a white solid. This product was recrystallized by slow evaporation from $\mathrm{CH}_{2} \mathrm{Cl}_{2} / \mathrm{MeOH}(1: 1, v / v)$ to obtain $1 \mathrm{aC}$ in crystalline form.

2.4.1. 1-Trifluoromethyl-2,3,5,6-tetrafluoro-4-[2-[4-[2-(4-methoxyphenyl)ethyn-1-yl]phenyl]ethyn-1yl]benzene (1aC)

Yield: $36 \%$ (white solid); mp: $168{ }^{\circ} \mathrm{C}$ determined by DSC; ${ }^{1} \mathrm{H}$ NMR $\left(\mathrm{CDCl}_{3}\right): \delta 3.84(\mathrm{~s}, 3 \mathrm{H})$, 6.88-6.91 (m, 2H), 7.47-7.50 (m, 6H); ${ }^{13} \mathrm{C}$ NMR $\left(\mathrm{CDCl}_{3}\right): \delta 55.5,74.9(\mathrm{t}, J=3.7 \mathrm{~Hz}), 87.7,92.8,104.7$, 108.8-109.3 (m), 109.7-109.8 (m, 1C), 114.3, 114.9, 120.7 (q, J = 273.6 Hz), 120.3, 125.9, 131.7, 132.2, 133.4, 142.9-145.7 (m), 145.8-148.3 (m), 160.2; ${ }^{19} \mathrm{~F} \mathrm{NMR}\left(\mathrm{CDCl}_{3}\right): \delta-56.67(\mathrm{t}, J=23.2 \mathrm{~Hz}, 3 \mathrm{~F}),-135.09$ (ddd, $J=18.1,18.1,5.7 \mathrm{~Hz}, 2 \mathrm{~F}),-141.27$ (m, 2F); IR (KBr): $v$ 2360, 2210, 1660, 1643, 1595, 1493, 1404, $1345 \mathrm{~cm}^{-1}$; HRMS $\left(\mathrm{FAB}^{+}\right) \mathrm{m} / \mathrm{z}[\mathrm{M}]^{+}$calcd for $\mathrm{C}_{24} \mathrm{H}_{11} \mathrm{OF}_{7}$ : 448.0698; found: 448.0699 .

2.4.2. 1-Trifluoromethyl-2,3,5,6-tetrafluoro-4-[2-[4-[2-(4-hexyloxyphenyl)ethyn-1-yl]phenyl]ethyn-1yl]benzene (1bC)

Yield: $32 \%$ (white solid); mp: $133^{\circ} \mathrm{C}$ determined by DSC; ${ }^{1} \mathrm{H}$ NMR $\left(\mathrm{CDCl}_{3}\right): \delta 0.91(\mathrm{t}, J=7.0 \mathrm{~Hz}$, $3 \mathrm{H}), 1.33-1.37(\mathrm{~m}, 4 \mathrm{H}), 1.43-1.50(\mathrm{~m}, 2 \mathrm{H}), 1.76-1.83(\mathrm{~m}, 2 \mathrm{H}), 3.98(\mathrm{t}, J=6.6 \mathrm{~Hz}, 2 \mathrm{H}), 6.87-6.89(\mathrm{~m}$, 2H), 7.45-7.48 (m, 2H), 7.52-7.59 (m, 4H); ${ }^{13} \mathrm{C} \mathrm{NMR}\left(\mathrm{CDCl}_{3}\right): \delta 14.1,22.7,25.8,29.3,31.7,68.3,74.9(\mathrm{t}$, $J=7.2 \mathrm{~Hz}), 87.6,93.0,104.7(\mathrm{t}, J=4.2 \mathrm{~Hz}), 108.9-109.2(\mathrm{~m}, 1 \mathrm{C}), 114.6,114.8,120.7(\mathrm{q}, J=273.6 \mathrm{~Hz}), 120.2$, 125.9, 131.6, 132.2, 133.3, 143.0-145.6 (m, 1C), 145.8-148.3 (m, 1C), 159.8 (one sp-carbon was overlapped with another alkyne carbon); ${ }^{19} \mathrm{~F}$ NMR $\left(\mathrm{CDCl}_{3}\right): \delta-56.77(\mathrm{t}, J=23.2 \mathrm{~Hz}, 3 \mathrm{~F}),-135.13(\mathrm{ddd}, J=18.2$, 18.2, $5.9 \mathrm{~Hz}, 2 \mathrm{~F}),-141.39$ (m, 2F); IR (KBr): $v$ 2957, 2894, 2360, 2211, 1659, 1606, $1594 \mathrm{~cm}^{-1}$; HRMS $\left(\mathrm{FAB}^{+}\right) \mathrm{m} / \mathrm{z}[\mathrm{M}]^{+}$calcd for $\mathrm{C}_{29} \mathrm{H}_{21} \mathrm{OF}_{7}: 518.1481$; found: 518.1484 .

\subsection{Preparation of CN-Substituted Bistolane 1aD}

In a $50 \mathrm{~mL}$ two-necked round-bottomed flask was placed 4-[2-(4-methoxyphenyl)ethyn-1-yl]phenylacetylene (3a, $0.47 \mathrm{~g}, 2.0 \mathrm{mmol})$ in THF (30 mL). The solution was cooled to $0{ }^{\circ} \mathrm{C}$ and then $n$-BuLi $\left(1.6 \mathrm{~mol} \mathrm{~L}^{-1}\right.$ hexane solution, $\left.1.3 \mathrm{~mL}, 2.0 \mathrm{mmol}\right)$ was added. The mixture was stirred at $0{ }^{\circ} \mathrm{C}$ for $0.5 \mathrm{~h}$. Then, perfluorobenzonitrile $(\mathbf{D}, 0.30 \mathrm{~mL}$, 
$2.4 \mathrm{mmol}$ ) was added dropwise at $0{ }^{\circ} \mathrm{C}$, and the resultant solution was continuously stirred at room temperature overnight. The reaction mixture was poured into saturated aqueous $\mathrm{NH}_{4} \mathrm{Cl}$ solution $(40 \mathrm{~mL})$. The crude product was extracted using AcOEt $(40 \mathrm{~mL}$, three times) and washed with brine ( $40 \mathrm{~mL}$, once). The organic layer was dried over anhydrous $\mathrm{Na}_{2} \mathrm{SO}_{4}$, filtered, and concentrated using a rotary evaporator. The resultant crude product was purified by silica-gel column chromatography using hexane/AcOEt $(20: 1, v / v)$ as an eluent, yielding coupling product $1 \mathrm{aD}(0.26 \mathrm{~g}, 0.64 \mathrm{mmol})$ in $32 \%$ yield as a yellow solid. This product was recrystallized by slow evaporation from $\mathrm{CH}_{2} \mathrm{Cl}_{2} / \mathrm{MeOH}$ (1:1, $v / v)$ to obtain $1 \mathrm{aD}$ in crystalline form.

2.5.1. 1-Cyano-2,3,5,6-tetrafluoro-4-[2-[4-[2-(4-methoxyphenyl)ethyn-1-yl]phenyl]ethyn-1- yl]benzene $(1 \mathrm{aD})$

Yield: $32 \%$ (yellow solid); mp: $195{ }^{\circ} \mathrm{C}$ determined by DSC; ${ }^{1} \mathrm{H}$ NMR $\left(\mathrm{CDCl}_{3}\right): \delta 3.84(\mathrm{~s}, 3 \mathrm{H})$, 6.87-6.92 (m, 2H), 7.47-7.50 (m, 6H), 7.52-7.61 (m, 4H); ${ }^{13} \mathrm{C}$ NMR $\left(\mathrm{CDCl}_{3}\right)$ : $855.5,75.2,87.7,93.1,93.3$, $107.1(\mathrm{dt}, J=84.9,4.9 \mathrm{~Hz}), 110.5(\mathrm{~d}, J=2.3 \mathrm{~Hz}), 111.2(\mathrm{t}, J=2.8 \mathrm{~Hz}), 114.3,114.9,120.0,126.3,131.7$, 132.3, 133.4, 145.3-146.0 (m), 147.8-148.7 (m), 160.2; ${ }^{19} \mathrm{~F} \mathrm{NMR}\left(\mathrm{CDCl}_{3}\right): \delta-133.19(\mathrm{ddd}, J=18.0,18.0$, $6.7 \mathrm{~Hz}, 2 \mathrm{~F}),-133.90(\mathrm{ddd}, J=18.0,17.9,6.1 \mathrm{~Hz}, 2 \mathrm{~F})$; IR (KBr): $v 2351,2207,1643,1595,1487,1478 \mathrm{~cm}^{-1}$; HRMS $\left(\mathrm{FAB}^{+}\right) \mathrm{m} / z[\mathrm{M}]^{+}$calcd for $\mathrm{C}_{24} \mathrm{H}_{11} \mathrm{NOF}_{4}$ : 405.0777; found: 405.0780 .

2.5.2. 1-Cyano-2,3,5,6-tetrafluoro-4-[2-[4-[2-(4-hexyloxyphenyl)ethyn-1-yl]phenyl]ethyn-1- yl]benzene (1bD)

Yield: $17 \%$ (yellow solid); mp: $154{ }^{\circ} \mathrm{C}$ determined by DSC; ${ }^{1} \mathrm{H}$ NMR $\left(\mathrm{CDCl}_{3}\right): \delta 0.91(\mathrm{t}, J=6.9 \mathrm{~Hz}$, $3 \mathrm{H}), 1.32-1.37(\mathrm{~m}, 4 \mathrm{H}), 1.44-1.48(\mathrm{~m}, 2 \mathrm{H}), 1.79$ (quin, $J=7.0 \mathrm{~Hz}, 2 \mathrm{H}), 3.98(\mathrm{t}, J=6.6 \mathrm{~Hz}, 2 \mathrm{H}), 6.87-6.90$ $(\mathrm{m}, 2 \mathrm{H}), 7.45-7.48(\mathrm{~m}, 2 \mathrm{H}), 7.52-7.59(\mathrm{~m}, 4 \mathrm{H}) ;{ }^{13} \mathrm{C} \mathrm{NMR}\left(\mathrm{CDCl}_{3}\right): \delta 14.2,22.7,25.8,29.3,31.7,68.3$, 75.5, 87.9, 93.3 (m), 93.3, 106.6-108.3 (m), 110.0, $111.3(\mathrm{~m}), 114.6,114.8,119.9,126.3,131.7,132.3,133.4$, 143.5-143.8 (m), 144.9-145.1 (m), 159.91; ${ }^{19} \mathrm{~F}$ NMR $\left(\mathrm{CDCl}_{3}\right): \delta-133.24(\mathrm{ddd}, J=19.5,17.8,6.3 \mathrm{~Hz}$, 2F), -133.94 (ddd, $J=19.5,17.8,6.3 \mathrm{~Hz}, 2 \mathrm{~F})$; IR (KBr): $v$ 2944, 2872, 2210, 1645, 1606, 1596, 1520, 1474, $1416 \mathrm{~cm}^{-1}$; HRMS $\left(\mathrm{FAB}^{+}\right) \mathrm{m} / z[\mathrm{M}]^{+}$calcd for $\mathrm{C}_{29} \mathrm{H}_{21} \mathrm{NOF}_{4}$ : 475.1559; found: 475.1549 .

\subsection{X-ray Crystallography}

Single crystals of $\mathbf{1 a B}$ and $\mathbf{1 a C}$ were obtained by a double purification protocol using column chromatography, followed by recrystallization $\left(\mathrm{CH}_{2} \mathrm{Cl}_{2} / \mathrm{MeOH}=1: 1, v / v\right.$ or $\mathrm{CH}_{2} \mathrm{Cl}_{2} /$ hexane $\left.=1: 1, v / v\right)$. The obtained single crystals were mounted on a glass fiber. $\mathrm{X}$-ray diffraction data were recorded using a Rigaku XtaLab mini diffractometer (Rigaku Corporation, Tokyo, Japan) or a Rigaku Saturn 724 diffractometer (Rigaku Corporation, Tokyo, Japan) equipped with a VariMax Mo optic system using $\operatorname{MoK} \alpha(\lambda=0.71075 \AA)$. The reflection data were integrated, scaled, and averaged using CrysAlisPro (ver. 1.171.38.46, Rigaku Oxford Diffraction, Rigaku Corporation, Tokyo, Japan, 2015). Empirical absorption corrections were applied using the SCALE3 ABSPACK scaling algorithm (CrysAlisPro, Rigaku Corporation, Tokyo, Japan). The structures were solved by a direct method (SHELXT-2014/5) and refined using a full-matrix least-squares method on $F^{2}$ for all reflections (SHELXL-2014/7) [24]. The crystallographic data were deposited into the Cambridge Crystallographic Data Centre (CCDC) database (CCDC 1908239 for $\mathbf{1 a B}$ and 1908240 for 1aC). These data can be obtained free of charge from the CCDC via www.ccdc.cam.ac.uk/data_request/cif.

\subsection{Computations}

All density functional theory (DFT) computations were performed using the Gaussian 09 (Revision C.01) package [25]. Geometry optimizations were executed using the CAM-B3LYP hybrid functional $[26,27]$ and the $6-31+G(d)$ basis set with an implicit solvation model, namely, the conductor-like polarizable continuum model (CPCM) [28-30], for $\mathrm{CH}_{2} \mathrm{Cl}_{2}$. The vertical excitation energies and dipole moments of the optimized structures were calculated using the time-dependent 
(TD)-DFT method at the same level as in the theory. To obtain the optimized structures in the excited $\left(\mathrm{S}_{1}\right)$ state, geometry optimizations were carried out using the TD-DFT method.

\subsection{Phase Transition Behavior}

The phase transition behavior of the fluorinated bistolanes was observed by polarizing optical microscopy (POM) using an Olympus BX53 microscope (Olympus Corporation, Tokyo, Japan) equipped with a cooling and heating stage (Linkam Scientific Instruments, 10002L, Surrey, UK). The thermodynamic behavior was determined using differential scanning calorimeter (DSC, Shimadzu, DSC-60 Plus, Kyoto, Japan) at heating and cooling rates of $5.0^{\circ} \mathrm{C} \mathrm{min}{ }^{-1}$ under a $\mathrm{N}_{2}$ atmosphere.

\subsection{Photophysical Behavior}

Ultraviolet-visible (UV-vis) absorption spectra were recorded using a JASCO V-500 (JASCO Corporation, Tokyo, Japan) absorption spectrometer. Steady-state PL spectra were obtained using a JASCO FP-8500 (JASCO Corporation, Tokyo, Japan) or a Hitachi F-7000 fluorometer (Hitachi Ltd., Tokyo, Japan). The absolute PL quantum yields were recorded using a calibrated integrating sphere with a Hamamatsu Photonics C11347-01 Absolute PL Quantum Yield Measurement System (Hamamatsu Photonics KK, Hamamatsu, Japan).

\section{Results and Discussion}

\subsection{Molecular Design}

Using DFT and TD-DFT calculations in the Gaussian 09 suite of programs, we examined the effect of the terminal substituent in each designed molecule on the electron-density distribution over the entire molecule. The geometries of $\mathbf{1 a B}-\mathbf{D}$ in the ground $\left(\mathrm{S}_{0}\right)$ and excited $\left(\mathrm{S}_{1}\right)$ states were optimized at the CAM-B3LYP/6-31+G(d) level of theory with the implicit solvation CPCM model for $\mathrm{CH}_{2} \mathrm{Cl}_{2}$. Figure 2 shows the structures of $\mathbf{1 a B}-\mathbf{D}$ and their calculated electrostatic potential maps, dipole moments along the long molecular axis $\left(\mu_{\|}\right)$, isodensity surfaces, and orbital energies for the highest occupied molecular orbital (HOMO) and lowest unoccupied molecular orbital (LUMO).

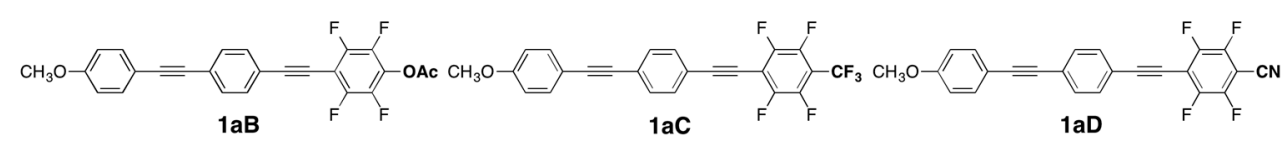

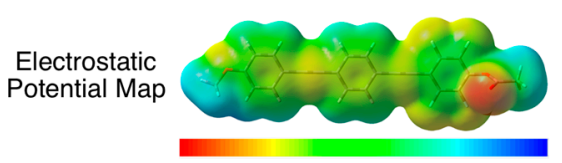

$\mu_{\|}[\mathrm{D}]$

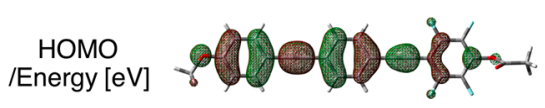

$-6.74$

LUMO

/Energy [eV]

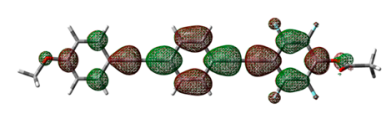

$-1.66$

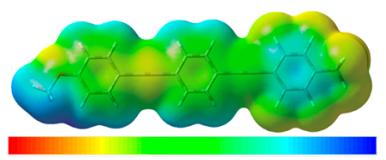

9.63

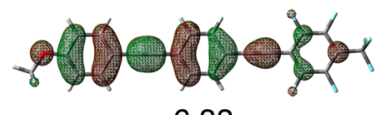

$-6.83$

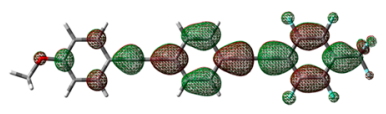

$-1.94$

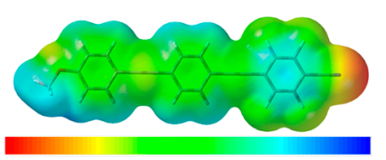

12.2
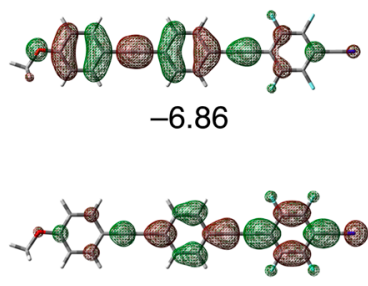

Figure 2. Chemical structures of $\mathbf{1 a B}-\mathbf{D}$ and their electrostatic potential maps, dipole moments $\left(\mu_{\|}\right)$ along the long molecular axis, isodensity surfaces with the color-bar (isovalue $=0.0004$ ), and orbital energies for the HOMO and LUMO in the $\mathrm{S}_{1}$ state.

The electrostatic potential maps of $\mathbf{1 a B}-\mathbf{D}$ reveal that the electron density at the fluorinated aromatic ring decreases in the following order: $\mathbf{1 a B}>\mathbf{1 a C}>\mathbf{1 a D}$. The dipole moment $\left(\mu_{\|}\right)$along the 
long molecular axis can be used to assess the electron-density distribution over the entire molecule quantitatively. AcO-substituted $\mathbf{1 a B}$ had the smallest $\mu_{\|}$value $(3.48 \mathrm{D})$, and this value increased when the $\mathrm{AcO}$ group was replaced by a $\mathrm{CF}_{3}$ or $\mathrm{CN}$ group $\left(\mu_{\|}=9.63 \mathrm{D}\right.$ for $1 \mathrm{aB}$ and $12.2 \mathrm{D}$ for $\left.1 \mathrm{aC}\right)$. These results clearly confirm that the incorporation of $\mathrm{AcO}, \mathrm{CF}_{3}$, and $\mathrm{CN}$ groups into the fluorinated bistolane scaffold can be used to systematically change the electron-density distribution over the entire molecule. The electron-density distribution also affected the molecular orbitals, with the orbital lobes in the HOMO largely localized on the relatively electron-rich aromatic rings, whereas the LUMO lobes were relatively localized on the electron-deficient aromatic rings. The orbital separation between the $\mathrm{HOMO}$ and LUMO in the $S_{1}$ state may contributable to unique PL behavior through intramolecular charge transfer [31]. The energy differences $\left(\Delta \mathrm{E}_{\mathrm{H}-\mathrm{L}}\right)$ between $\mathrm{HOMO}$ and LUMO levels were $5.08 \mathrm{eV}$ for $\mathbf{1 a B}, 4.89 \mathrm{eV}$ for $\mathbf{1 a C}$, and $4.67 \mathrm{eV}$ for $\mathbf{1 a D}$. Thus, $\mathbf{1 a D}$ is expected to show a PL band in the long-wavelength region, with the PL wavelength shifting towards shorter wavelengths as the transition energy increases, i.e., $\mathbf{1 a B}>\mathbf{1 a C}$. Theoretical calculations for $\mathbf{1 b B}-\mathbf{D}$, bearing long alkoxy substituents, also provided similar $\mu_{\|}$and HOMO/LUMO distributions (see Supplementary Materials), assuming that the alkoxy-substituent does not affect in the electron density distribution. Consequently, systematic control of the electron-density distribution induced by modulating the electronic character of the terminal substituent should realize luminescence tuning for the fluorinated luminophores. According to our previous study, modulation of terminal substituents also influences the LC behavior [21,23], not only through changes in the electron-density distribution but also in the steric bulkiness of the substituent. Thus, systematic modulation of the terminal substituent in 1aB-D may also allow control of the LC behavior.

\subsection{Synthesis and Crystal Structure}

Based on the aforementioned molecular design, fluorinated bistolanes $1 \mathrm{aB}-\mathrm{C}$ with a $\mathrm{CH}_{3} \mathrm{O}$ group and $\mathbf{1 b B}-\mathbf{D}$ with a hexyloxy $\left(\mathrm{C}_{6} \mathrm{H}_{13} \mathrm{O}\right)$ moiety were synthesized according to the procedure shown in Scheme 1. AcO-substituted $\mathbf{1 a B}$ was obtained in $48 \%$ yield by the $\mathrm{Pd}(0)$-catalyzed Sonogashira cross-coupling reaction of $\mathbf{3 a}$, readily accessible from $\mathbf{2 a}$ [21,23], with $\mathbf{B}$. In contrast, $\mathrm{CF}_{3}$-substituted $1 \mathrm{aC}$ and $\mathrm{CN}$-substituted $1 \mathrm{aD}$ were obtained in $36 \%$ or $32 \%$ yield, respectively, by nucleophilic aromatic substitution of the in situ generated lithium acetylide derived from 3a with perfluorotoluene and perfluorobenzonitrile, respectively [32]. In a similar manner, $\mathrm{C}_{6} \mathrm{H}_{13} \mathrm{O}$-substituted analogue $\mathbf{1 b B}$ was prepared in $54 \%$ yield through a Sonogashira cross-coupling reaction and $\mathbf{1 b C}$ and $\mathbf{1 b D}$ were prepared in $32 \%$ and $17 \%$ yields, respectively, through nucleophilic substitution reactions. Each fluorinated bistolane was purified by column chromatography and recrystallization from a 1:1 solution of $\mathrm{CH}_{2} \mathrm{Cl}_{2}$ (good solvent) and $\mathrm{MeOH}$ or hexane (poor solvent). The structure of each compound was confirmed by ${ }^{1} \mathrm{H},{ }^{13} \mathrm{C}$, and ${ }^{19} \mathrm{~F} N \mathrm{NM}$, IR, and HRMS and the spectra indicated that the purity was sufficient to evaluate the LC and PL behaviors.

Among the fluorinated bistolanes, $\mathrm{AcO}$-substituted $\mathbf{1 a B}$ and $\mathrm{CF}_{3}$-substituted $\mathbf{1 a C}$ furnished single crystals appropriate for X-ray crystallographic analysis. 1aB crystalized with a monoclinic crystal structure in the $P 2_{1}$ space group with two molecular units in the unit cell. As shown in Figure 3a, the three aromatic rings were found to be almost coplanar, although there may be a rapid equilibrium between the coplanar and twisted conformations through free rotation of the $C_{\mathrm{sp}}-C_{\mathrm{sp} 2}$ single bonds [33]. The packing structure (Figure $3 \mathrm{~b}$ ) revealed several close contacts that were shorter than the sums of the van der Waals radii (carbon: $170 \mathrm{pm}$, hydrogen: $120 \mathrm{pm}$, and fluorine: $148 \mathrm{pm}$ ) [34]: $H_{\text {alkyl }} \cdots C_{\mathrm{sp} 2}(288$ pm), $H_{\text {aryl }} \cdots C_{\text {sp }}(284 \mathrm{pm}), H_{\text {aryl }} \cdots F(253 \mathrm{pm}), H_{\text {alkyl }} \cdots F(246 \mathrm{pm}), H_{\text {aryl }} \cdots O(257 \mathrm{pm})$. Thus, the crystal lattice of $1 \mathrm{aB}$ contains two $\mathrm{CH}-\pi$ interactions and three hydrogen bonding interactions. In contrast, $\mathbf{1 a C}$ crystalized with a monoclinic crystal structure in the $P 2_{1} / c$ space group with four molecular units in the unit cell. As shown in Figure $3 c$, each $1 \mathrm{aC}$ molecule was also found to be coplanar with several short contacts (Figure 3d), such as $C_{\mathrm{sp} 2} \cdots C_{\mathrm{sp} 2}(332 \mathrm{pm}), H_{\mathrm{aryl}} \cdots F(251 \mathrm{pm}), C_{\mathrm{sp} 2} \cdots F(314 \mathrm{pm})$, and $F \cdots F$ $(265 \mathrm{pm})$. Thus, $1 \mathrm{aC}$ also formed a tight packing structure with one $\pi-\pi$ interaction, one hydrogen bonding interaction, and one lone-pair- $\pi$ interaction $[35,36]$. 
(a)

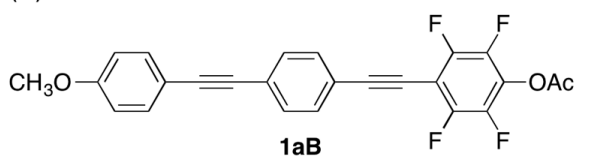

Top view

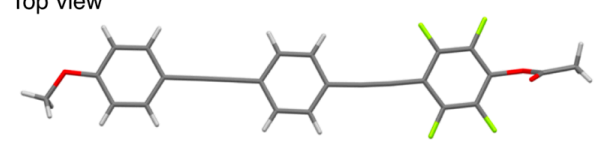

Side view

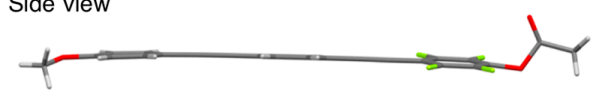

(c)

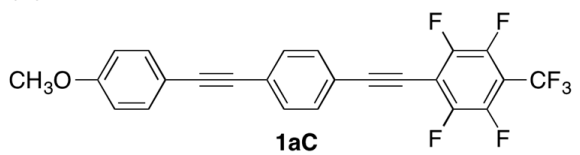

Top view

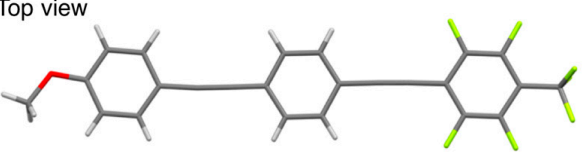

Side view

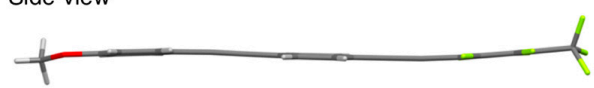

(b)

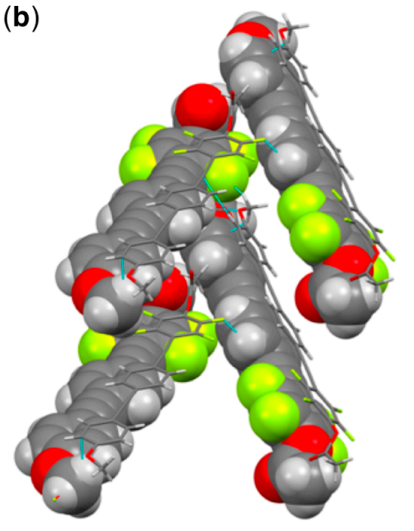

(d)

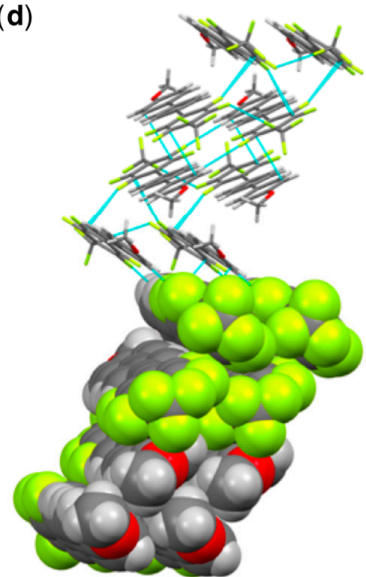

Figure 3. Molecular and crystal structures of (a) $\mathbf{1 a B}$ and (c) 1aC. Packing structures of (b) $1 \mathrm{aB}$ and (d) 1aC. The light-blue lines in the packing structures indicate close contacts shorter than the sum of van der Waals radii (C: 170 pm, H: 120 pm, F: 148 pm).

\subsection{Phase Transition Behavior}

The phase transition behavior of fluorinated bistolanes $\mathbf{1 a B}-\mathbf{D}$ and $\mathbf{1 b B}-\mathbf{D}$ was investigated using POM and DSC. Figure 4 shows the phase transition behavior observed during the 2 nd heating cooling processes and the microphotographic images of the LC phases.

(a)

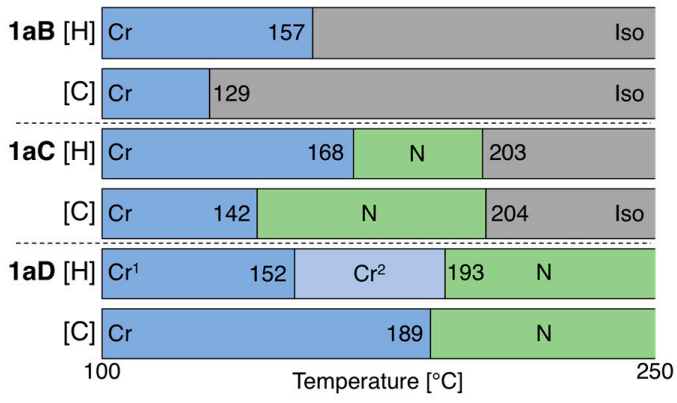

(b)

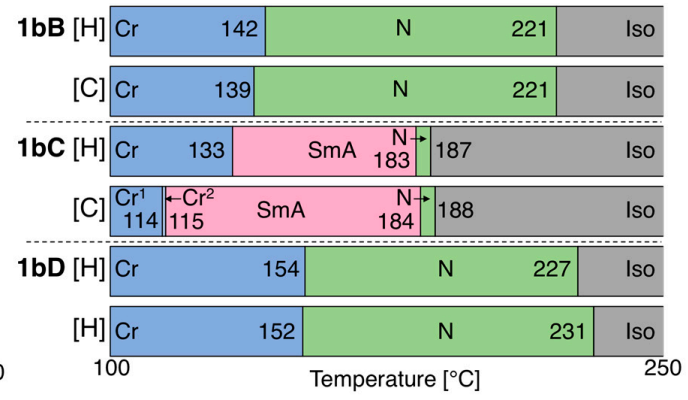

(c)
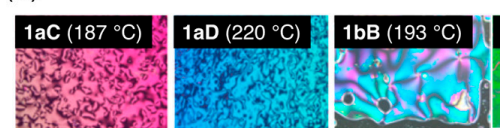

$1 \mathrm{bC}\left(140^{\circ} \mathrm{C}\right.$

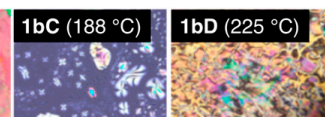

Figure 4. Phase transition behavior of (a) $\mathbf{1 a B}-\mathbf{D}$ and (b) $\mathbf{1 b B}-\mathbf{D}$ during the 2 nd heating $[\mathrm{H}]$ and cooling [C] processes. Abbreviations: $\mathrm{Cr}$, crystal; $\mathrm{SmA}$, smectic $\mathrm{A} ; \mathrm{N}$, nematic; and Iso, isotropic phases. (c) Microphotographic images recorded by POM during the cooling process. 
Among $1 \mathbf{a B}-\mathbf{D}$ with a methoxy group at one molecular terminal and an electron-withdrawing substituent at the other, AcO-substituted 1aB exhibited no LC behavior, as evidenced by the dramatic change in the POM images from nonfluidic bright-viewing to fluidic dark-viewing fields during both the heating and cooling processes. The steric hindrance of the $\mathrm{AcO}$ group and the dipole moment $\left(\mu_{\perp}\right)$ along the short molecular axis induced by the carbonyl moiety in the AcO group likely make it difficult to order structures in the condensed phase, resulting in a direct phase transition to the isotropic (Iso) phase. In contrast, the POM images of $1 \mathrm{aC}$ with a $\mathrm{CF}_{3}$ group and $\mathbf{1 a D}$ with a $\mathrm{CN}$ group displayed fluidic bright-viewing fields between the crystal ( $\mathrm{Cr}$ ) and Iso phases; POM and DSC measurements only revealed a single LC phase for $\mathbf{1 a C}$ and $\mathbf{1 a D}$. As the microphotographic images of $\mathbf{1 a C}$ and $\mathbf{1 a D}$ display a four-brushed Schlieren texture, which is typical of nematic $(\mathrm{N})$ LC phases, the single LC phases of $1 \mathrm{aC}$ and $1 \mathrm{aD}$ are assigned as $\mathrm{N}$ phases. The melting temperature $\left(T_{\mathrm{m}}\right.$, defined as the phase transition temperature between the $\mathrm{Cr}$ and LC phases) and the clearing temperature ( $T_{\mathfrak{c}}$, defined as the phase transition temperature between the LC an Iso phases) are much higher for $\mathbf{1 a D}$ than for $\mathbf{1 a C}$ (Figure 3a). This behavior is consistent with the linear and rigid structure of the $\mathrm{CN}$ group, which induces tight packing in an antiparallel direction owing to the large $\mu_{\|}$value [37-39].

Changing the length of the flexible chain at the molecular terminal by replacing $\mathrm{CH}_{3} \mathrm{O}$ with $\mathrm{C}_{6} \mathrm{H}_{13} \mathrm{O}$ affected the LC behavior. 1bB-D all showed LC phases, and the $T_{\mathrm{m}}$ and $T_{\mathrm{c}}$ values for $\mathbf{1 b B}-\mathbf{D}$ were dramatically decreased compared with the corresponding values for $\mathbf{1 a B}-\mathbf{D}$. Typically, such stabilization of LC phases can be attributed to the introduction of a longer flexible unit [23]. The POM and DSC measurements revealed that AcO-substituted $\mathbf{1 b B}$ and $\mathrm{CN}$-substituted $\mathbf{1 b D}$ displayed only a N LC phase owing to the steric bulkiness of $\mathrm{AcO}$ and the rigid linear rigid structure of $\mathrm{CN}$ with a large $\mu_{\|}$value. However, $\mathrm{CF}_{3}$-substituted $\mathbf{1 b C}$ exhibited both SmA and N LC phases, analogous to those previously reported for $\mathbf{1 b A}$. Thus, a suitable choice of substituent at the molecular terminal is important for achieving precise control of the LC behavior, including the LC phase, phase transition temperature, and LC temperature range.

\subsection{PL Behavior in the Solution Phase}

Next, we examined the photophysical behavior of the fluorinated bistolanes. First, we investigated the absorption and PL behavior in $\mathrm{CH}_{2} \mathrm{Cl}_{2}$ solution $\left(\sim 1.0 \times 10^{-5} \mathrm{~mol} \mathrm{~L}^{-1}\right.$ for absorption and $1.0 \times$ $10^{-6} \mathrm{~mol} \mathrm{~L}^{-1}$ for PL). Figure $5 \mathrm{a}, \mathrm{b}$ shows the absorption and PL spectra, respectively, of $1 \mathrm{aB}-\mathbf{D}$ (solid lines) and $\mathbf{1 b B}-\mathbf{D}$ (dashed lines). Figure $5 \mathrm{c}$ shows photographs of the PL colors and the corresponding Commission Internationale d'Eclairage (CIE) chromaticity diagram. The photophysical data are listed in Table 1.

Table 1. Photophysical data for $1 \mathrm{aB}-\mathbf{D}$ and $\mathbf{1 b B}-\mathbf{D}$ in $\mathrm{CH}_{2} \mathrm{Cl}_{2}$ solution.

\begin{tabular}{|c|c|c|c|c|c|c|}
\hline & \multirow{2}{*}{$\lambda_{\mathrm{abs}}(\mathrm{nm})^{1}(\varepsilon)^{2}$} & \multicolumn{2}{|c|}{ Ground $\left(S_{0}\right)$ State $^{3}$} & \multirow{2}{*}{$\lambda_{\mathrm{PL}}(\mathrm{nm})^{4}\left(\Phi_{\mathrm{PL}}\right)^{4,5}$} & \multicolumn{2}{|c|}{ Excited $\left(S_{1}\right)$ State $^{6}$} \\
\hline & & $\mu_{\|}$(D) & HOMO/LUMO (eV) & & $\mu_{\|}$(D) & HOMO/LUMO (eV) \\
\hline $1 \mathrm{aB}$ & $333(55.2)$ & 1.91 & $-7.09 /-1.30$ & $410(0.85)$ & 3.48 & $-6.74 /-1.66$ \\
\hline $1 \mathrm{aC}$ & $341(48.1)$ & 7.22 & $-7.13 /-1.58$ & $444(0.99)$ & 9.63 & $-6.83 /-1.94$ \\
\hline $1 \mathrm{aD}$ & $356(46.7)$ & 9.67 & $-7.15 /-1.87$ & $488(0.91)$ & 12.2 & $-6.86 /-2.19$ \\
\hline $1 b B$ & 335 (54.5) & 2.27 & $-7.07 /-1.29$ & $414(0.86)$ & 3.93 & $-6.72 /-1.65$ \\
\hline $1 b C$ & $343(52.5)$ & 7.51 & $-7.12 /-1.58$ & $451(0.95)$ & 10.0 & $-6.81 /-1.94$ \\
\hline $1 b D$ & $360(44.8)$ & 9.95 & $-7.13 /-1.86$ & $493(0.87)$ & 12.6 & $-6.84 /-2.19$ \\
\hline
\end{tabular}

${ }^{1}$ Concentration of the solution: $1.0 \times 10^{-5} \mathrm{~mol} \mathrm{~L}^{-1} \cdot{ }^{2}$ Molar extinction coefficient $\left(10^{-3} \mathrm{~L} \mathrm{~mol}^{-1} \mathrm{~cm}^{-1}\right) \cdot{ }^{3}$ Obtained by DFT calculations at the CAM-B3LYP/6-31+G(d) level of theory. ${ }^{4}$ Concentration of the solution: $1.0 \times 10^{-6}$ mol L ${ }^{-1}$. ${ }^{5}$ Measured using a calibrated integrating sphere system. ${ }^{6}$ Obtained by TD-DFT calculations at the CAM-B3LYP/6-31+G(d) level of theory.

In $\mathrm{CH}_{2} \mathrm{Cl}_{2}$ solution, $\mathrm{CH}_{3} \mathrm{O}$-Substituted 1aB-D each exhibited a single absorption band and the maximum absorption wavelength $\left(\lambda_{\text {abs }}\right)$ varied significantly depending on the electron-withdrawing substituent: $333 \mathrm{~nm}$ (AcO-substituted 1aB), $341 \mathrm{~nm}\left(\mathrm{CF}_{3}\right.$-substituted 1aC), and $356 \mathrm{~nm}$ (CN-substituted 1aD) (Figure 5a), in which the $\lambda_{\max }$ in the calculated UV-Vis spectra obtained from TD-DFT calculation 
resulted in a similar tendency: $338 \mathrm{~nm}$ (AcO-substituted $1 \mathrm{aB}), 347 \mathrm{~nm}\left(\mathrm{CF}_{3}\right.$-substituted 1aC), and $360 \mathrm{~nm}$ (CN-substituted 1aD) (Figure S21). As listed in Table 1, the $\mu_{\|}$values in the $\mathrm{S}_{0}$ state were calculated to be $\mathbf{1 a B}(1.91 \mathrm{D})<\mathbf{1 a C}(7.22 \mathrm{D})<\mathbf{1 a D}(9.67 \mathrm{D})$, indicating a strong correlation between the $\lambda_{\mathrm{abs}}$ and $\mu_{\|}$ values. Upon excitation at $\lambda_{\mathrm{abs}}, \mathbf{1} \mathbf{a B}-\mathbf{D}$ in $\mathrm{CH}_{2} \mathrm{Cl}_{2}$ each displayed a single PL band at a maximum PL wavelength $\left(\lambda_{\mathrm{PL}}\right)$ of $410-488 \mathrm{~nm}$ with a high PL efficiency $\left(\Phi_{\mathrm{PL}}=0.85-0.91\right)$ (Figure $\left.5 \mathrm{~b}\right)$. As shown in Figure 5c, 1aB-D emitted deep-blue, blue PL, light-green PL, respectively, and the PL colors can also be quantitatively evaluated using the CIE chromaticity diagram. Similar to $\lambda_{\mathrm{abs}}, \lambda_{\mathrm{PL}}$ also exhibited a shift towards longer wavelengths depending on the $\mu_{\|}$value. Replacing the $\mathrm{CH}_{3} \mathrm{O}$ substituent with the longer $\mathrm{C}_{6} \mathrm{H}_{13} \mathrm{O}$ unit did not change the absorption or PL spectra significantly owing to the similar $\mu_{\|}$values. These results clearly demonstrate that the electron-density distribution induced by the electron-withdrawing substituent is an important parameter for controlling the photophysical properties in the solution phase.
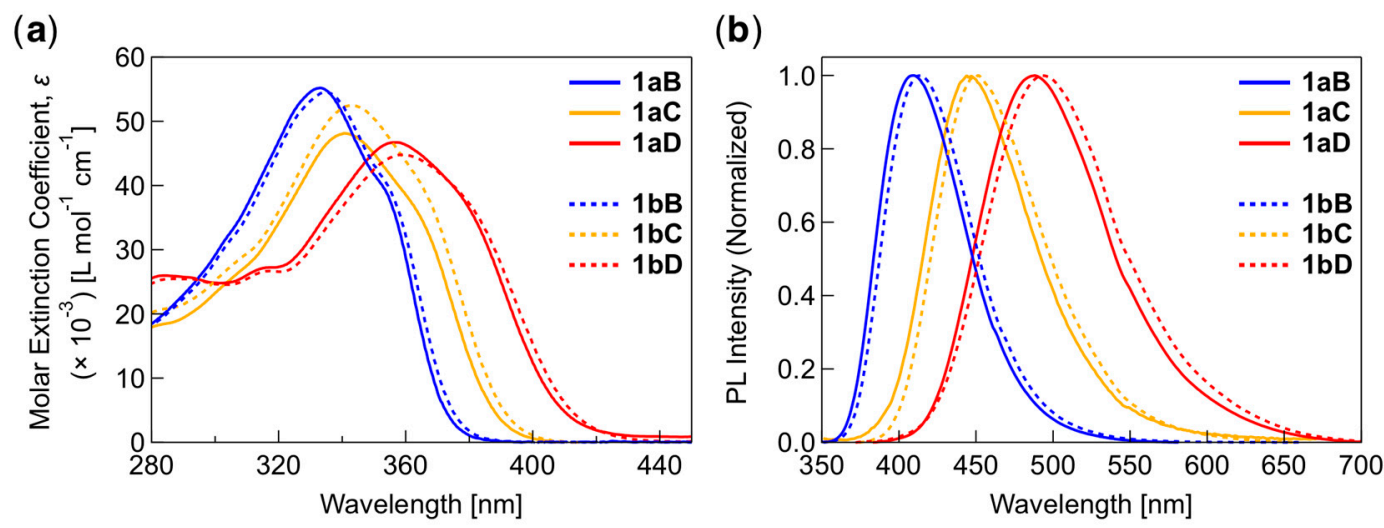

(c)
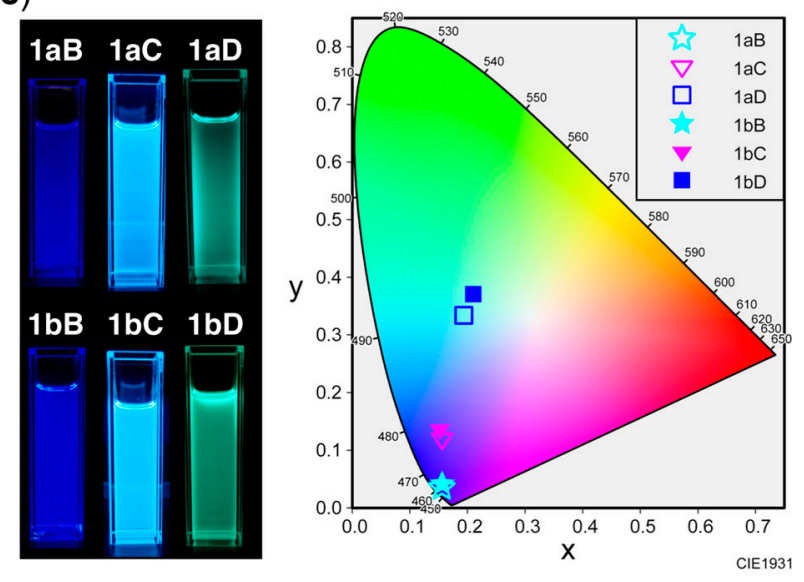

Figure 5. (a) Absorption spectra of $\mathbf{1 a B}-\mathbf{D}$ (solid lines) and $\mathbf{1 b B}-\mathbf{D}$ (dashed lines) in $\mathrm{CH}_{2} \mathrm{Cl}_{2}$ $\left(1.0 \times 10^{-5} \mathrm{~mol} \mathrm{~L}^{-1}\right) ;(\mathbf{b})$ photoluminescence (PL) spectra of $\mathbf{1 a B}-\mathbf{D}$ (solid lines) and $\mathbf{1} \mathbf{b B}-\mathbf{D}$ (dashed lines) in $\mathrm{CH}_{2} \mathrm{Cl}_{2}\left(1.0 \times 10^{-6} \mathrm{~mol} \mathrm{~L}^{-1}\right)$; (c) photographs under ultraviolet (UV) irradiation $\left(\lambda_{\mathrm{ex}}=365 \mathrm{~nm}\right)$ and $\mathrm{CIE}$ chromaticity diagram for the $\mathrm{PL}$ in $\mathrm{CH}_{2} \mathrm{Cl}_{2}$ solution.

TD-DFT calculations revealed that the $\mathrm{HOMO} \rightarrow \mathrm{LUMO}$ transition corresponded with the lowest-energy excitation with a large oscillator strength. Considering that the energy gap between the HOMO and LUMO $\left(\Delta \mathrm{E}_{\mathrm{H}-\mathrm{L}}\right)$ in the $\mathrm{S}_{0}$ state decreases in the order $1 \mathrm{aB}(5.69 \mathrm{eV})>1 \mathrm{aC}(5.55 \mathrm{eV})>$ $1 \mathrm{aD}(5.28 \mathrm{eV})$, increasing the $\mu_{\|}$value results in a narrower $\Delta \mathrm{E}_{\mathrm{H}-\mathrm{L}}$ and a shift of $\lambda_{\text {abs }}$ towards longer wavelengths: $\mathbf{1 a B}(338 \mathrm{~nm})<\mathbf{1 a C}(347 \mathrm{~nm})<\mathbf{1 a D}(360 \mathrm{~nm}) . \Delta \mathrm{E}_{\mathrm{H}-\mathrm{L}}$ in the $\mathrm{S}_{1}$ state exhibited a similar tendency $(\mathbf{1 a B}>\mathbf{1 a C}>\mathbf{1 a D})$, corresponding to the order of the $\mu_{\|}$values. Thus, these results clearly indicate that the electronic transitions for absorption and PL can be controlled by tuning $\mu_{\|}$. 
The PL colors of luminophores with large $\mu_{\|}$values have often been reported to show obvious variations depending on the solvent polarity [40]. Therefore, we tested the PL sensing properties of $\mathrm{CF}_{3}$-substituted $\mathbf{1 b C}$ as a representative fluorinated bistolane in various solvents. Figure 6 shows the observed PL behavior, and the photophysical data are summarized in Table 2.

(a)

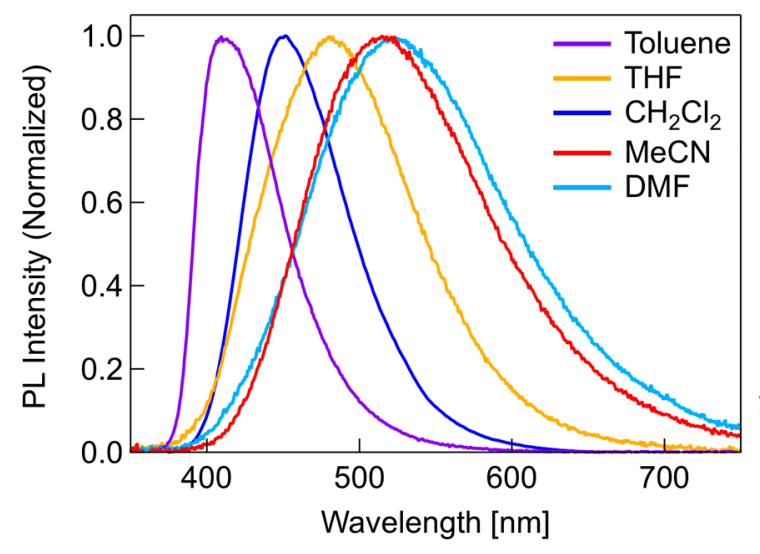

(b)
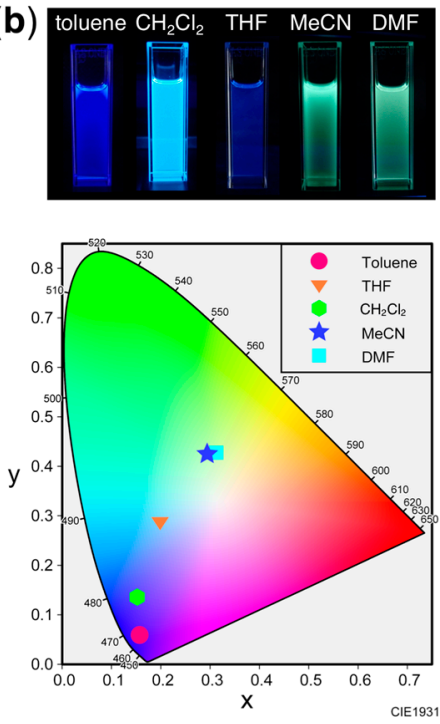

Figure 6. (a) PL spectra of $1 \mathbf{b C}$ in various solvents (concentration: $\left.1.0 \times 10^{-6} \mathrm{~mol} \mathrm{~L}^{-1}\right)$; (b) photographs under UV irradiation $\left(\lambda_{\mathrm{ex}}=365 \mathrm{~nm}\right)$ and CIE chromaticity diagram for the PL in various solvents.

Table 2. Photophysical properties of $1 \mathrm{bC}$ in various solvents.

\begin{tabular}{|c|c|c|c|c|c|}
\hline Solvent $(\varepsilon)^{1}$ & Toluene (2.38) & THF (7.58) & $\mathrm{CH}_{2} \mathrm{Cl}_{2}(8.93)$ & MeCN (35.9) & DMF (36.7) \\
\hline$\lambda_{\mathrm{PL}}(\mathrm{nm})^{2}$ & 409 & 482 & 451 & 518 & 523 \\
\hline$\Phi_{\mathrm{PL}}^{3}$ & 0.79 & 0.55 & 0.95 & 0.58 & 0.40 \\
\hline
\end{tabular}

Irradiating $\mathbf{1 b C}$ at $343 \mathrm{~nm}$ in less polar toluene $(\varepsilon=2.38$, where $\varepsilon$ is a dielectric constant at $25^{\circ} \mathrm{C}$ and an indicator of solvent polarity [40]) produced deep-blue PL with a single PL band at $\lambda_{\mathrm{PL}}=409 \mathrm{~nm}$, which was shifted towards shorter wavelengths by $0.282 \mathrm{eV}$ compared with the $\lambda_{\mathrm{PL}}$ in $\mathrm{CH}_{2} \mathrm{Cl}_{2}(\varepsilon=8.93)$. In contrast, dramatic shifts towards longer wavelengths were observed when more polar solvents, e.g., $\operatorname{MeCN}(\varepsilon=35.9)$ and DMF $(\varepsilon=36.7)$, were employed; based on the CIE diagram, greenish-yellow PL was observed in both cases. Although THF $(\varepsilon=7.58)$ is less polar than $\mathrm{CH}_{2} \mathrm{Cl}_{2}$, the PL band $\left(\lambda_{\mathrm{PL}}=482 \mathrm{~nm}\right)$ was shifted towards longer wavelengths by $0.177 \mathrm{eV}$. The unique PL behavior in THF is likely due to the oxygen atom, which allows THF to easily solvate $\mathbf{1 b C}$ with its large $\mu_{\|}$value through intermolecular interactions, such as hydrogen bonding, and may promote the nonradiative deactivation from the $S_{1}$ to the $S_{0}$ state [41-43]. Consequently, it was successfully demonstrated that the fluorinated bistolanes can be applied as PL sensing materials for solvent polarity.

\subsection{PL Behavior in the Crystal Phase}

To our delight, we found that $\mathbf{1} \mathbf{a B}-\mathbf{D}$ and $\mathbf{1 b B}-\mathbf{D}$ crystals prepared by recrystallization via a slow evaporation technique exhibited PL. Figure 7 shows the obtained PL spectra acquired, and the photophysical data are listed in Table 3. 
(a)

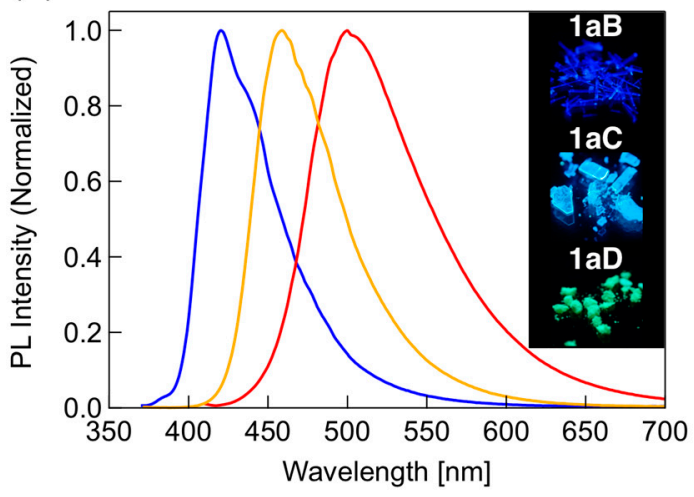

(b)

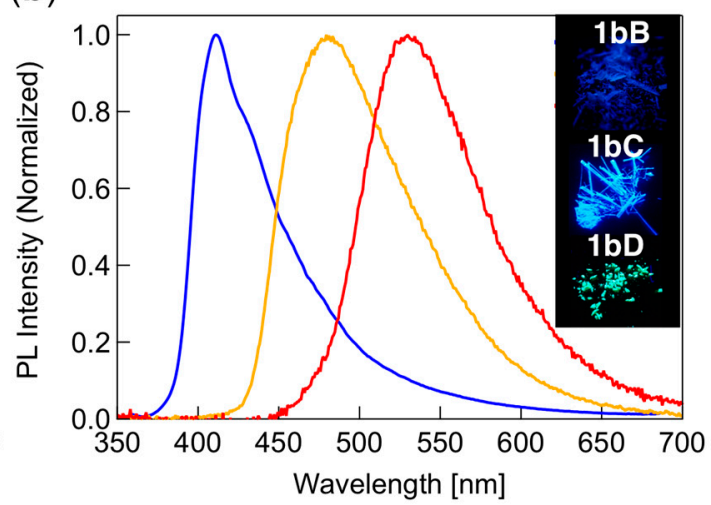

(c)

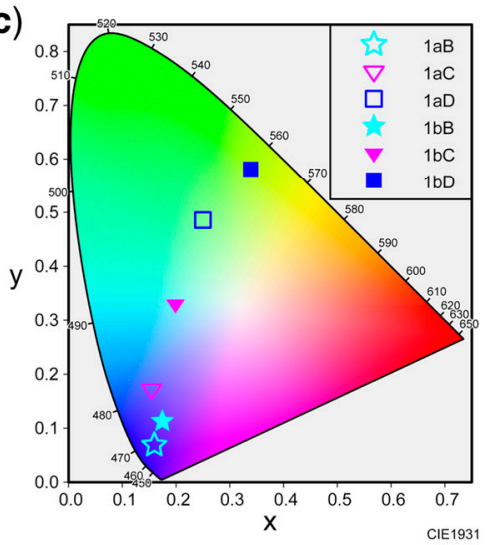

Figure 7. PL spectra of (a) 1aB-D and (b) 1bB-D crystals; (c) CIE chromaticity diagram calculated from the corresponding PL spectra.

Table 3. Photophysical properties of $1 \mathrm{aB}-\mathrm{D}$ and $\mathbf{1 b B}-\mathbf{D}$ crystals.

\begin{tabular}{ccc}
\hline Compound & $\boldsymbol{\lambda}_{\mathbf{P L}}(\mathbf{n m})^{\mathbf{1}}$ & $\boldsymbol{\Phi}_{\mathbf{P L}}{ }^{\mathbf{2}}$ \\
\hline $\mathbf{1 a B}$ & 420 & 0.48 \\
$\mathbf{1 a C}$ & 459 & 0.80 \\
$\mathbf{1 a D}$ & 500 & 0.36 \\
$\mathbf{1 b B}$ & $414(418)$ & 0.17 \\
$\mathbf{1 b C}$ & $479(443)$ & 0.73 \\
$\mathbf{1 b D}$ & $526(527)$ & 0.31 \\
\hline
\end{tabular}

${ }^{1}$ Upon excitation at $358 \mathrm{~nm}$ for $\mathbf{1 a B}, 361 \mathrm{~nm}$ for $\mathbf{1 a C}, 400 \mathrm{~nm}$ for $\mathbf{1 a D}$, and $320 \mathrm{~nm}$ for $\mathbf{1 b B}-\mathbf{D}$. The values in parentheses are the PL maximum wavelengths in the LC state upon excitation at $320 \mathrm{~nm}$. ${ }^{2}$ Measured using a calibrated integrating sphere system.

As shown in Figure $7 \mathrm{a}, \mathrm{b}, \lambda_{\mathrm{PL}}$ changed dramatically depending on the electron-withdrawing substituent, even in crystals: $414-420 \mathrm{~nm}$ (deep-blue PL) for AcO-substituted 1aB and 1bB, 459-479 nm (blue to light-blue PL) for $\mathrm{CF}_{3}$-substituted $1 \mathrm{aC}$ and $1 \mathrm{bC}$, and 500-526 nm (yellowish-green PL) for $\mathrm{CN}$-substituted $1 \mathrm{aD}$ and $\mathbf{1 b D}$. Compared with the $\lambda_{\mathrm{PL}}$ values in $\mathrm{CH}_{2} \mathrm{Cl}_{2}$ solution, those observed for the crystals were slightly shifted towards longer wavelengths, which may be due to quick deactivation via nonradiative processes owing to intermolecular interactions in the condensed phases. As discussed above, exchanging the $\mathrm{CH}_{3} \mathrm{O}$ group for a longer $\mathrm{C}_{6} \mathrm{H}_{13} \mathrm{O}$ moiety did not have a significant effect on the electronic structure; however, an intriguing band shift of $0.113 \mathrm{eV}$ for $1 \mathrm{aC}$ vs. $\mathbf{1 b C}$ and $0.123 \mathrm{eV}$ for $\mathbf{1 a D}$ vs. $\mathbf{1 b D}$ was observed. According to our previous reports [21,23], this change in the PL behavior likely originates from a dramatic change in the aggregated structure induced by the difference in alkoxy chain length. Similar to the trend observed for the $\mathrm{PL}$ in $\mathrm{CH}_{2} \mathrm{Cl}_{2}$ solution, a relatively strong correlation was observed between $\mu_{\|}$and $\lambda_{\mathrm{PL}}$ in the crystals. These results demonstrate that the PL behavior of the 
fluorinated bistolanes can also be modulated in crystal by controlling $\mu_{\|}$via the electron-withdrawing character of the terminal substituent.

\subsection{PL Behavior in the LC Phase}

Finally, owing to the fluorinated bistolanes possessing LC phases and unique PL characteristics, we examined the PL behavior in the LC phase under thermal conditions. As representative examples, frozen $\mathrm{LC}$ samples of $1 \mathrm{bB}, 1 \mathrm{bC}$, and $1 \mathrm{bD}$ were obtained by rapid cooling in a dry-ice bath after a suitable LC phase was observed. The obtained PL spectra are shown in Figure 8.

(a) For $1 \mathrm{bB}$

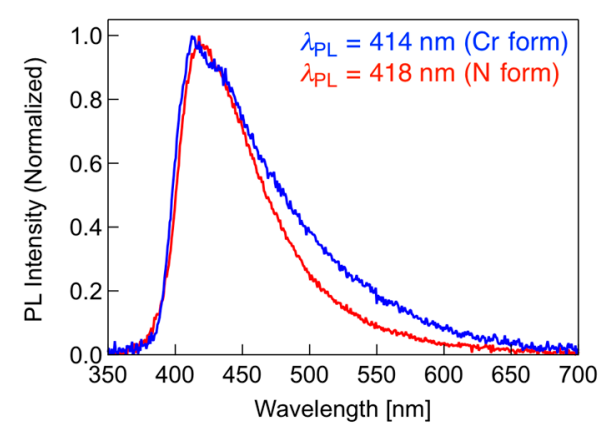

(b) For $1 \mathrm{bc}$

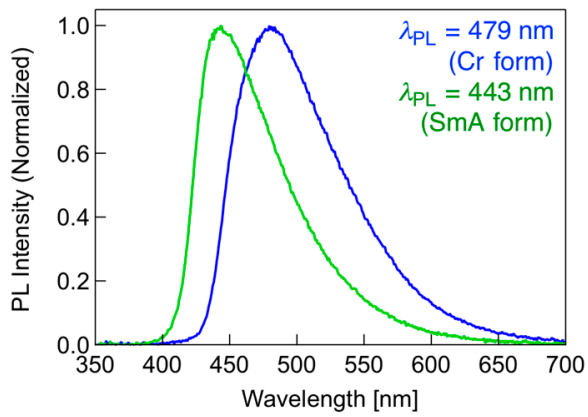

(c) For $\mathbf{1 b D}$

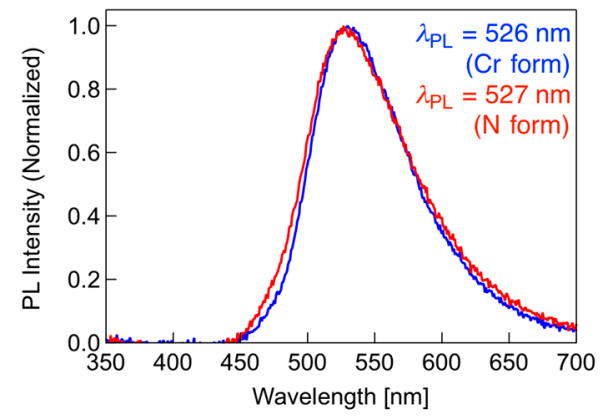

Figure 8. PL spectra of the Cr and LC phases of (a) $1 \mathbf{b B},(\mathbf{b}) \mathbf{1 b C}$, and (c) $1 \mathrm{bD}$ upon excitation at $320 \mathrm{~nm}$.

When the N LC samples of AcO-substituted $\mathbf{1 b B}$ and $\mathrm{CN}$-substituted $1 \mathrm{bD}$ were irradiated at $320 \mathrm{~nm}$ light, single PL bands were observed at $\lambda_{\mathrm{PL}}=418$ and $527 \mathrm{~nm}$, respectively, which were almost identical to those in the $\mathrm{Cr}$ phase (Figure 8a,c). Interestingly, as shown in Figure 8b, the initial $\mathrm{Cr}$ sample of $\mathrm{CF}_{3}$-substituted $1 \mathrm{bC}$ showed light-blue PL $\left(\lambda_{\mathrm{PL}}=479 \mathrm{~mm}\right)$, but a significant shift to shorter wavelengths was observed after the phase transition to the SmA phase, leading to deep-blue PL $\left(\lambda_{\mathrm{PL}}=443 \mathrm{~nm}\right)$, which is almost identical to that in $\mathrm{CH}_{2} \mathrm{Cl}_{2}$ solution. It is anticipated that rearrangement of the molecular aggregates during the $\mathrm{Cr} \rightarrow \mathrm{SmA}$ phase transition results in loose molecular packing owing to thermally activated molecular motion and monomeric emission characteristics. Accordingly, it can be concluded that the PL of fluorinated bistolanes can be controlled not only by tuning the electron-density distribution but also by modulating molecular aggregation through thermal phase transitions, which is a promising approach for realizing functional PL sensing materials, such as PL thermometers.

\section{Conclusions}

In conclusion, we designed and synthesized fluorinated bistolanes with an alkoxy substituent at one molecular terminal and various electron-withdrawing substituent at the other terminal via a four-step protocol. The phase transition temperatures of the fluorinated bistolanes were found to depend significantly on the terminal substituent, with the LC behavior affected by both the steric and 
electronic nature of the substituent. The PL behavior in solution clearly revealed that both $\lambda_{\mathrm{PL}}$ and the PL color changed dramatically depending on the $\mu_{\|}$value. The present fluorinated bistolanes also showed relatively strong PL in the crystal phase, with the PL behavior modulated not only by $\mu_{\|}$but also by molecular aggregation. Notably, the PL emission of a $\mathrm{CF}_{3}$-substituted fluorinated bistolane was significantly shifted towards shorter wavelengths by $0.210 \mathrm{eV}$ via a phase transition from the $\mathrm{Cr}$ to the SmA LC phase. As the PL behavior of the fluorinated bistolanes can be tuned by the electron-density distribution as well as the aggregated structure in condensed phases, this molecular design approach offers a useful method for fabricating PL materials that can be easily tuned by using molecular properties or external stimuli.

Supplementary Materials: The following are available online at http://www.mdpi.com/2076-3417/9/9/1905/s1, Figures S1-S18: NMR spectra, Table S1: crystallographic data, Figure S19: DSC thermograms, Tables S2-S6: phase transition behavior and thermodynamic parameter, Figure S20: photophysical spectra in solution, Figure S21: comparison between calculated and experimental UV-vis spectra, Figure S22: photophysical spectra in crystal, Figure S23: PL spectra in LC phases, Figures S24-S34: HOMO and LUMO diagram, Tables S7-S18: cartesian coordinate for calculated molecules.

Author Contributions: Conceptualization, S.Y.; methodology, S.Y. and M.M.; investigation, S.Y., M.M., T.A., T.K. (Toshio Kubota) and T.K. (Tsutomu Konno); writing-original draft preparation, S.Y., M.M. and T.K. (Tsutomu Konno); writing-review and editing, S.Y., M.M., T.A., T.K. (Toshio Kubota) and T.K. (Tsutomu Konno); visualization, S.Y. and M.M.; supervision, S.Y.; project administration, S.Y.; funding acquisition, S.Y.

Funding: This research was funded by JSPS KAKENHI, Grant-in-Aid for Scientific Research (C) (Grant No. JP18K05262).

Acknowledgments: We sincerely acknowledge Kensuke Naka and Hiroaki Imoto (Kyoto Institute of Technology) and Osamu Tsutsumi (Ritsumeikan University) for the PL measurements in the crystal phase.

Conflicts of Interest: The authors declare no conflict of interest.

\section{References}

1. Yang, Y.; Zhao, Q.; Feng, W.; Li, F. Luminescent chemodosimeters for bioimaging. Chem. Rev. 2013, 113, 192-270. [CrossRef]

2. Bünzli, J.-C.G. Lanthanide luminescence for biomedical analyses and imaging. Chem. Rev. 2010, 110, 2729-2755. [CrossRef]

3. Hemmer, E.; Acosta-Mora, P.; Méndez-Ramos, J.; Fischer, S. Optical nanoprobes for biomedical applications: Shining a light on upconverting and near-infrared emitting nanoparticles for imaging, thermal sensing, and photodynamic therapy. J. Mater. Chem. B 2017, 5, 4365-4392. [CrossRef]

4. Hou, J.-T.; Ren, W.X.; Li, K.; Seo, J.; Sharma, A.; Yu, X.-Q.; Kim, J.S. Fluorescent bioimaging of pH: From design to applications. Chem. Soc. Rev. 2017, 46, 2076-2090. [CrossRef]

5. Zhou, J.; Feng, W.; Sun, Y.; Li, F. Upconversion luminescent materials: Advances and applications. Chem. Rev. 2015, 115, 395-465. [CrossRef]

6. Bui, T.-T.; Goubard, F.; Ibrahim-Ouali, M.; Gigmes, D.; Dumur, F. Recent advances on organic blue thermally activated delayed fluorescence (TADF) emitters for organic light-emitting diodes (OLEDs). Beilstein J. Org. Chem. 2018, 14, 282-308. [CrossRef]

7. Jhulki, S.; Moorthy, J.N. Small molecular hole-transporting materials (HTMs) in organic light-emitting diodes (OLEDs): Structural diversity and classification. J. Mater. Chem. C 2018, 6, 8280-8325. [CrossRef]

8. Grimsdale, A.C.; Chan, K.L.; Martin, R.E.; Jokisz, P.G.; Holmes, A.B. Synthesis of light-emitting conjugated polymers for applications in electroluminescent devices. Chem. Rev. 2009, 109, 897-1091. [CrossRef]

9. Leung, N.L.C.; Xie, N.; Yuan, W.; Liu, Y.; Wu, Q.; Peng, Q.; Miao, Q.; Lam, J.W.Y.; Tang, B.Z. Restriction of intramolecular motions: The general mechanism behind aggregation-induced emission. Chem. Eur. J. 2014, 20, 15349-15353. [CrossRef]

10. Shen, P.; Zhuang, Z.; Zhao, Z.; Tang, B.Z. AIEgens based on main group heterocycles. J. Mater. Chem. C 2018, 6, 11835-11852. [CrossRef]

11. He, Z.; Ke, C.; Tang, B.Z. Journey of aggregation-induced emission research. ACS Omega 2018, 3, 3267-3277. [CrossRef] 
12. Kirsch, P. Modern Fluoroorganic Chemistry: Synthesis, Reactivity, Applications, 2nd ed.; Wiley-VCH: Weinheim, Germany, 2013; pp. 7-21.

13. O'Hagan, D. Understanding organofluorine chemistry. An introduction to the C-F bond. Chem. Soc. Rev. 2008, 37, 308-319. [CrossRef]

14. Konno, T. Trifluoromethylated internal alkynes: Versatile building blocks for the preparation of various fluorine-containing molecules. Synlett 2014, 25, 1350-1370. [CrossRef]

15. Konno, T. Trifluoromethyl $\left(\mathrm{CF}_{3}\right)$ group insertion methods in stereoselective synthesis. In Stereoselective Synthesis of Drugs and Natural Products; Andrunshko, V., Andrunshko, N., Eds.; John Wiley \& Sons: Hoboken, NJ, USA, 2013; pp. 769-806.

16. Yamada, S.; Konno, T. New types of negative dielectric anisotropy liquid crystals: Synthesis of $\mathrm{CF}_{2} \mathrm{CF}_{2}$-carbocyclic mesogens and an evaluation of their liquid crystal characteristics. In Chemical Elements (Fluorine, Rhodium and Rubidium): Properties, Synthesis and Applications; Huff, A., Ed.; Nova Science Publishers: New York, NY, USA, 2018; pp. 53-92.

17. Tamamoto, K.; Yamada, S.; Konno, T. Practical tetrafluoroethylene fragment installation through a coupling reaction of (1,1,2,2-tetrafluorobut-3-en-1-yl)zinc bromide with various electrophiles. Beilstein J. Org. Chem. 2018, 14, 2375-2383. [CrossRef]

18. Yamada, S.; Mitsuda, A.; Miyano, K.; Tanaka, T.; Morita, M.; Agou, T.; Kubota, T.; Konno, T. Development of novel solid-state light-emitting materials based on pentafluorinated tolane fluorophores. ACS Omega 2018, 3, 9105-9113. [CrossRef]

19. Yamada, S.; Miyano, K.; Agou, T.; Kubota, T.; Konno, T. 2-Chloroalkoxy-substituted pentafluorinated bistolanes as novel light-emitting liquid crystals. Crystals 2019, 9, 195. [CrossRef]

20. Yamada, S.; Tanaka, T.; Ichikawa, T.; Konno, T. Novel V- and Y-shaped light-emitting liquid crystals with pentafluorinated bistolane-based luminophores. ACS Omega 2019, 4, 3922-3932. [CrossRef]

21. Yamada, S.; Morita, M.; Agou, T.; Kubota, T.; Ichikawa, T.; Konno, T. Thermoresponsive luminescence properties of polyfluorinated bistolane-type light-emitting liquid crystals. Org. Biomol. Chem. 2018, 16, 5609-5617. [CrossRef] [PubMed]

22. Yamada, S.; Morita, M.; Konno, T. Multi-color photoluminescence induced by electron-density distribution of fluorinated bistolane derivatives. J. Fluorine Chem. 2017, 202, 54-64. [CrossRef]

23. Yamada, S.; Miyano, K.; Konno, T.; Agou, T.; Kubota, T.; Hosokai, T. Fluorine-containing bistolanes as light-emitting liquid crystalline molecules. Org. Biomol. Chem. 2017, 15, 5949-5958. [CrossRef]

24. Sheldrick, G.M. Crystal structure refinement with SHELXL. Acta Crystallogr. 2015, C71, 3-8. [CrossRef]

25. Frish, M.J.; Trucks, G.W.; Schlegel, H.B.; Scuseria, G.E.; Robb, M.A.; Cheeseman, J.R.; Scalmani, G.; Barone, V.; Mennucci, B.; Peterson, G.A.; et al. Gaussian 09, Revision C.01; Gaussian, Inc.: Wallingford, CT, USA, 2013.

26. Yanai, T.; Tew, D.P.; Handy, N.C. A new hybrid exchange-correlation functional using the Coulomb-attenuating method (CAM-B3LYP). Chem. Phys. Lett. 2004, 393, 51-57. [CrossRef]

27. Okuno, K.; Shigeta, Y.; Kishi, R.; Nakano, M. Non-empirical tuning of CAM-B3LYP functional in time-dependent density functional theory for excitation energies of diarylethene derivatives. Chem. Phys. Lett. 2013, 585, 201-206. [CrossRef]

28. Andzelm, J.; Kölmel, C.; Klamt, A. Incorporation of solvent effects into density functional calculations of molecular energies and geometries. J. Chem. Phys. 1995, 103, 9312-9320. [CrossRef]

29. Barone, V.; Cossi, M. Quantum calculation of molecular energies and energy gradients in solution by a conductor solvent model. J. Phys. Chem. A 1998, 102, 1995-2001. [CrossRef]

30. Cossi, M.; Rega, N.; Scalmani, G.; Barone, V. Energies, structures, and electronic properties of molecules in solution with the C-PCM solvation model. J. Comput. Chem. 2003, 24, 669-681. [CrossRef]

31. Misra, R.; Bhattacharyya, S.P. Intramolecular Charge Transfer: Theory and Applications; Wiley-VCH: Weinheim, Germany, 2018; pp. 4-19.

32. Liu, C.; Zhao, H.; Zhao, H.; Wang, Z.; Zhang, B. Base-promoted direct and highly selective alkynylation of electron-deficient ocatafluorotoluene. RSC Adv. 2015, 5, 31993-31997. [CrossRef]

33. Levitus, M.; Schmieder, K.; Ricks, H.; Shimizu, K.D.; Bunz, U.H.F.; Garcia-Garibay, M.A. Steps to demarcate the effects of chromophore aggregation and planarization in poly(phenyleneethynylene)s. 1. Rotationally interrupted conjugation in the excited states of 1,4-bis(phenylethynyl)benzene. J. Am. Chem. Soc. 2001, 123, 4259-4265. [CrossRef]

34. Bondi, A. van der Waals volumes and radii. J. Phys. Chem. 1964, 68, 441-451. [CrossRef] 
35. Mooibroek, T.J.; Gamez, P.; Reedijk, J. Lone pair- $\pi$ interactions: A new supramolecular bond? CrystEngComm 2008, 10, 1501-1515. [CrossRef]

36. Neel, A.J.; Hilton, M.J.; Sigman, M.S.; Toste, F.D. Exploiting non-covalent $\pi$ interactions for catalyst design. Nature 2017, 543, 637-646. [CrossRef]

37. Hird, M.; Toyne, K.J.; Goodby, J.W.; Gray, G.W.; Minter, V.; Tuffin, R.P.; McDonnell, D.G. Synthesis, mesomorphic behaviour and optical anisotropy of some novel materials for nematic mixtures of high birefringence. J. Mater. Chem. 2004, 14, 1731-1743. [CrossRef]

38. Seed, A.J.; Toyne, K.J.; Goodby, J.W.; Hird, M. Synthesis, transition temperatures, and optical properties of various 2,6-disubstituted naphthalenes and related 1-benzothiophenes with butylsulfanyl and cyano or isothiocyanato terminal groups. J. Mater. Chem. 2000, 10, 2069-2080. [CrossRef]

39. Seed, A.J.; Toyne, K.J.; Goodby, J.W. Synthesis of the series of monofluoro-substituted 4-butylsulfanyl-4'-cyanobiphenyls and effect of the position of fluorine within the core on refractive indices, optical anisotropies, polarisabilities and order parameters. J. Mater. Chem. 1995, 5, 2201-2207. [CrossRef]

40. Misra, R.; Bhattacharyya, S.P. Intramolecular Charge Transfer: Theory and Applications; Wiley-VCH: Weinheim, Germany, 2018; pp. 115-144.

41. Li, M.; Han, J.; Zhao, H.; Liu, Z.; Ma, L.; Sun, C.; Yin, H.; Shi, Y. Investigation of the intermolecular hydrogen bonding effects on the intramolecular charge transfer process of coumarin 340 in tetrahydrofuran solvent. J. Cluster Sci. 2018, 29, 585-592. [CrossRef]

42. Kukhta, N.A.; Volyniuk, D.; Grazulevicius, J.V.; Sini, G. Blue versus yellow emission in bipolar fluorenone derivatives: The impact of aggregation and hydrogen bonding. J. Mater. Chem. C 2018, 6, 1679-1692. [CrossRef]

43. Kukhta, N.A.; da Silva Filho, D.A.; Volyniuk, D.; Grazulevicius, J.V.; Sini, G. Can fluorenone-based compounds emit in the blue region? Impact of the conjugation length and the ground-state aggregation. Chem. Mater. 2017, 29, 1695-1707. [CrossRef]

(C) 2019 by the authors. Licensee MDPI, Basel, Switzerland. This article is an open access article distributed under the terms and conditions of the Creative Commons Attribution (CC BY) license (http://creativecommons.org/licenses/by/4.0/). 